\title{
Peroral direct cholangioscopy for recurrent bile duct stones, using an ultrathin upper endoscope
}

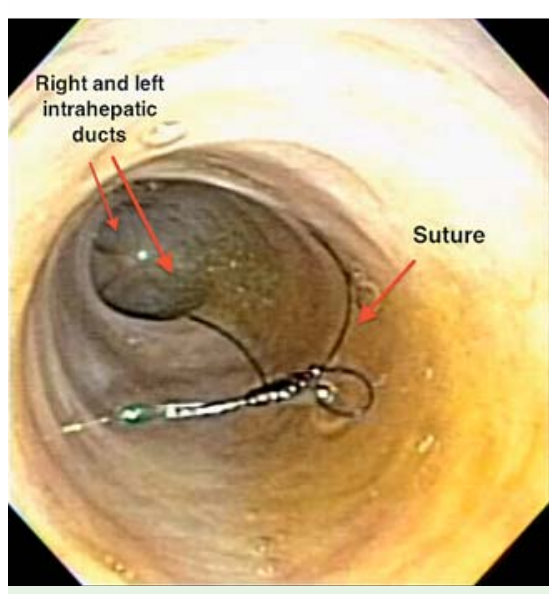

Fig. 1 Endoscopic view of the suture inside the common hepatic duct.

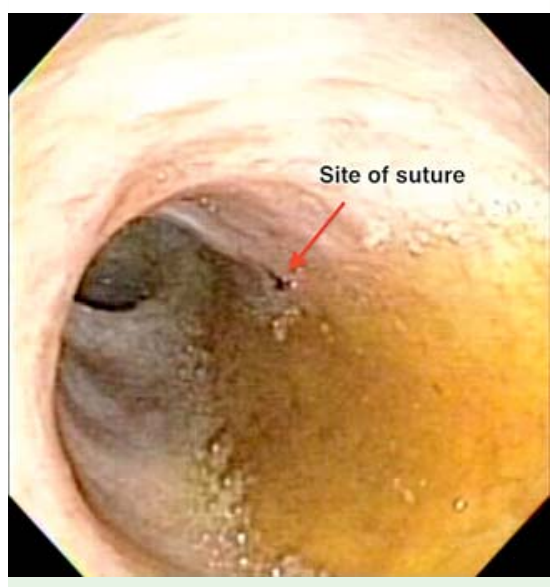

Fig. 3 The common hepatic duct after removal of suture.

Multiple recurrences of bile duct stones are rare, and occur when there is bile stasis and a nidus for stone conglomeration $[1,2]$. Endoscopic examination of the bile duct has traditionally been difficult and is not routinely performed. We report the first case of management of recurrent bile duct stones using an ultrathin upper endoscope.

A 54-year-old woman presented for endoscopic retrograde cholangiography (ERC) for removal of biliary stents placed for recurrent bile duct stones. She had first presented 20 years ago with symptomatic

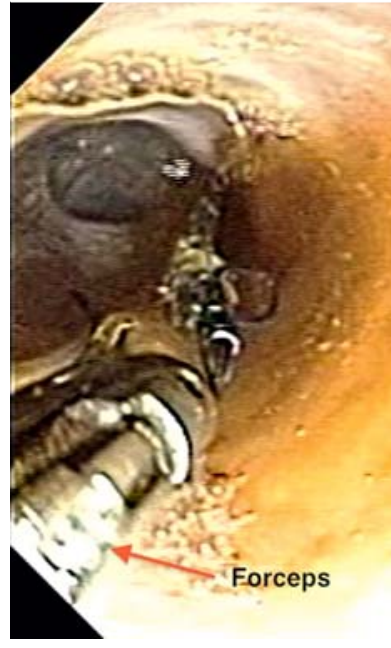

cholelithiasis. An open cholecystectomy with bile duct exploration and T-tube placement was carried out, and no common bile duct stones were seen. After 2 days, due to persistent elevation of serum bilirubin, endoscopic retrograde cholangiopancreatography with sphincterotomy was done and a few stones extracted. The pancreatic duct was normal. The patient presented again 12 years later with symptomatic bile duct stones. ERC was carried out and multiple stones extracted. Over the next 8 years, six ERCs were carried out for recurrent, symptomatic bile duct stones, and each time stones and sludge were extracted. The patient was asymptomatic in the intervals between the procedures. During the present ERC, the biliary stents were removed and a cholangiogram obtained. No filling defects were seen. Due to history of recurrent stone formation, we decided to perform direct cholangioscopy to find a possible nidus for stone formation. A super-stiff wire (Boston Scientific, Natick, Massachusetts, USA) was placed within the branch of the intrahepatic duct and the duodenoscope removed. The wire was backloaded onto the ultrathin endoscope XGIF-PV70N5 (Olympus America Inc., Center Valley, Pennsylvania, USA) with an outer diameter of $5.4 \mathrm{~mm}$ and an accessory channel of
$2 \mathrm{~mm}$. The ultrathin endoscope was advanced over the wire to the major papilla and the common bile duct cannulated. The common bile duct appeared normal. About $2 \mathrm{~cm}$ proximal to cystic duct take off, knotted suture material was seen protruding into the lumen ( Fig. 1). This was thought to be a possible nidus for recurrent stone formation [3-5]. Pediatric biopsy forceps were passed through the biopsy channel and used to remove the sutures by gentle tugging ( Figs. 2 and 3). The suture was 4-0 Prolene and was probably placed after common bile duct exploration during cholecystectomy. There were no post-procedure complications. The patient remains asymptomatic 16 months post procedure.

\section{Competing interests: None}

Endoscopy_UCTN_Code_TTT_1AR_2AJ

\section{Agrawal ${ }^{1}$, A. Chak ${ }^{2}$}

${ }^{1}$ University Texas Southwestern Medical Center - Gastroenterology, Dallas, Texas, USA

2 University Hospitals Case Medical Center - Gastroenterology, Cleveland, Ohio, USA 


\section{References}

1 Ando T, Tsuyuguchi T, Okugawa T et al. Risk factors for recurrent bile duct stones after endoscopic papillotomy. Gut 2003; 52: $116-121$

2 Ban JL, Hirose FM, Benfield JR. Foreign bodies of the biliary tract: report of two patients and a review of the literature. Ann Surg 1972; 176: $102-107$

3 Orr $K B$. Suture material as a nidus for formation of common bile duct stones. Aust N Z J Surg 1980; 50: $493-494$
4 Smoczynski M, Mittlener S. Suture material as a nidus of common bile duct calculi. Endoscopy 1995; 27: 279

5 Kim K-H, Jang B-I, Kim T-N. A common bile duct stone formed by suture material after open cholecystectomy. Korean J Intern Med 2007; 22: $279-282$

Bibliography

DOI $10.1055 / \mathrm{s}-0029-1244224$

Endoscopy 2010; 42: E190-E191

(c) Georg Thieme Verlag KG Stuttgart · New York . ISSN 0013-726X

\section{Corresponding author}

D. Agrawal

Rhode Island Hospital - Gastroenterology 593 Eddy Street APC

406 Providence 02906

Rhode Island

USA

Fax: +401-444-6194

deepak_ag@yahoo.com 